INTERNATIONAL JOURNAL OF MULTIDisciplinaRy RESEARCH AND ANALYSis

ISSN(print): 2643-9840, ISSN(online): 2643-9875

Volume 05 Issue 01 January 2022

DOI: 10.47191/ijmra/v5-i1-09, Impact Factor: 6.072

Page No.- 67-72

\title{
Ionic State of Molybdenum in Sulfuric Uterine Solutions of Rhenium Sorption and its Extraction
}

\author{
Nargiza Bekbutaeva1, Khasan Sharipov², Galina Lukomskaya ${ }^{3}$, Alibek Bekbutaev, Farrux \\ Tashaliev $^{5}$, Azamat Safarov 6 \\ ${ }^{1}$ Leading Engineer of the Science Department of JSC "Almalyk MMC", Republic of Uzbekistan, Almalyk \\ ${ }^{2}$ Director of the Institute of General and Inorganic Chemistry of the Academy of Sciences, Republic of Uzbekistan, Tashkent \\ ${ }^{3}$ Laboratory engineer of the scientific and technological center of JSC "AMMC" Republic of Uzbekistan, Almalyk \\ ${ }^{4}$ Chief metallurgist of JSC "Almalyk MMC", Republic of Uzbekistan, Almalyk \\ ${ }^{5}$ Leading Engineer of the Science Department of JSC "Almalyk MMC", Republic of Uzbekistan, Almalyk \\ ${ }^{6}$ Technician at the Institute of General and Inorganic Chemistry Academy of Sciences of the Republic of Uzbekistan
}

ABSTRACT: The results of studies of the forms of finding and methods of extracting molybdenum from acidic solutions with a high concentration of sulfuric acid are presented. Ion-exchange resins of various modifications were tested to determine the most effective for molybdenum during its sorption from a sulfuric acid solution.

KEY WORDS: Electrochromatography; Burning; Ion Exchange; Extraction; Cation; Anion; Macroporous Weakly Basic Anion Exchanger.

\section{INTRODUCTION}

The technology of obtaining (extracting) molybdenum from sulphide raw materials includes oxidative roasting in furnaces and hydrometallurgical processing of roasted products [1,2]. In the process of oxidative roasting of sulphide raw materials, gases containing sulfur oxides are formed. Sulfurous gases, as a rule, enter the wet gas cleaning system to obtain sulfuric acid solutions. As a result of the formation of fine dust of molybdenite raw materials during firing, molybdenum is present in sulfuric acid solutions in certain quantities $[3,4]$.

Considering that the content of molybdenum in sulfuric acid solutions of wet gas cleaning systems can range from $1 \mathrm{~g} / \mathrm{I}$ to 5 $6 \mathrm{~g} / \mathrm{l}$, additional extraction of molybdenum is of practical interest.

Ion exchange sorption is used in molybdenum hydrometallurgy [5-8.]. Sorption of molybdenum is carried out from solutions of nitric acid decomposition and solutions of soda leaching of molybdenum-containing raw materials. Molybdenum in such solutions is present in either cationic or anionic form. Therefore, the sorption of molybdenum from solutions of nitric acid decomposition and soda leaching proceeds efficiently. Molybdenum is sorbed from solutions by cation and anion exchangers.

Both strongly basic and weakly basic resins have a maximum capacity for molybdenum in weakly acidic media in the $\mathrm{pH}$ range from 5 to 2, those. in the area of existence in solutions of polymer anions such as $\mathrm{Mo}_{7} \mathrm{O}^{-6}{ }_{24}$ and $\mathrm{Mo}_{4} \mathrm{O}^{-2}{ }_{13}$, etc. With an increase in the acid concentration, the capacity of resins for molybdenum decreases due to the competing action of the acid anion [9]. The presence of cationic and anionic forms of molybdenum in sulfuric acid solutions complicates the choice of ion-exchange resin and sorption of molybdenum in general.

\section{OBJECTS AND METHODS OF RESEARCH}

The sulphate mother liquor of rhenium sorption was investigated. The chemical composition of the sulphate mother liquor is presented in Table 1. This solution also contains rhenium, which comes with the initial sulphide molybdenum raw material and sublimes in the process of oxidative roasting and is captured in the wet gas cleaning system. Rhenium is extracted mainly by ionexchange sorption on weakly basic anion exchangers. The presence of molybdenum negatively affects the sorption of rhenium, because molybdenum reduces the capacity of the weakly basic anion exchanger for rhenium. After sorption of rhenium, up to 


\section{Ionic State of Molybdenum in Sulfuric Uterine Solutions of Rhenium Sorption and its Extraction}

$90 \%$ remains in mother liquors molybdenum from the original sulfuric acid solution of wet gas cleaning. The studies were carried out on solutions with a content of 3-8 $\mathrm{g} / \mathrm{I}$.

Table 1. The composition of the sulphate mother liquor

\begin{tabular}{|l|l|l|l|l|}
\hline $\mathrm{H}_{2} \mathrm{SO}_{4}, \mathrm{~g} / \mathrm{l}$ & $\mathrm{Re}, \mathrm{mg} / \mathrm{l}$ & $\mathrm{Mo}, \mathrm{g} / \mathrm{l}$ & $\mathrm{Cu}, \mathrm{mg} / \mathrm{l}$ & $\mathrm{Fe}, \mathrm{mg} / \mathrm{l}$ \\
\hline $300-350$ & $<10$ & $3-8$ & $10-25$ & $35-40$ \\
\hline
\end{tabular}

\section{RESULTS OF THE INVESTIGATIONS AND DISCUSSION}

To determine the ratio of cationic and anionic forms, electrochromatography of the sulfuric mother liquor and oxidative titration with $0.1 \mathrm{~N}$ potassium permanganate solution were carried out. to determine the reduced forms of molybdenum.

For studies on the extraction of molybdenum from sulfuric acid solutions, sorption with the use of cation exchangers and anion exchangers (sorbents) of various modifications was considered.

Microstructure analysis was performed using an electron microscope .........with EDX energy dispersive analysis attachment. X-ray diffraction patterns of sorbents were obtained on an XRD diffractometer .........CuK $\alpha$-radiation. Vibrational spectra (IR, Raman spectra) were recorded on an IR Fourier spectrometer in the range 400-4000 cm-1 and in the range $300-1200$ $\mathrm{cm}-1$ on a Raman spectrometer ........

The determination of molybdenum sorption indices was carried out under statistical conditions at the ratio of the volumes of solution and sorbent $\mathrm{Vp}: \mathrm{Vc}=10: 1$. For sorption from dilute solutions and solutions adjusted to a given acid content or $\mathrm{pH}$, we used the volumes of solutions corresponding to the initial ratio of 10: 1 in terms of the amount of molybdenum.

IV. RESULTS OF THE INVESTIGATIONS AND DISCUSSION

It was established by electrochromatography and sorption that in sulfuric acid solutions with a sulfuric acid content of 300$400 \mathrm{~g} / \mathrm{l}$, the main forms of molybdenum compounds are complex molybdenyl sulfate ions $\left[\mathrm{MoO}_{2}\left(\mathrm{SO}_{4}\right)_{\mathrm{n}}\right]^{-(2 \mathrm{n}-2)}$ and molybdenyl ion $\mathrm{MoO}_{2}{ }^{2+}$ in the composition $\mathrm{MoO}_{2} \mathrm{SO}_{4}$.

As can be seen from the data in Table 2, when the original mother liquor is diluted with water up to $200 \mathrm{~g} / \mathrm{I}$ and $100 \mathrm{~g} / \mathrm{I}$ with respect to sulfuric acid, the proportion of the cationic form of molybdenum increases. With a similar neutralization of the sulfuric acid solution with ammonia.

The solution retains a high content of sulfate ion. As a result, the proportion of the cationic form of molybdenum is somewhat less than when diluting a sulfuric acid solution with water. Taking into account the existing concepts, it can be assumed that anionic complexes of the $\left[\mathrm{MoO}_{2}\left(\mathrm{SO}_{4}\right) \mathrm{n}\right]^{-}{ }_{(2 \mathrm{n}-2)}$ type are present in the sulfuric acid solution; molybdenyl sulfate complexes, and MoO22 + cations in the composition of neutral molecules of molybdenyl sulfate $\mathrm{MoO}_{2} \mathrm{SO}_{4}$.

Table 2. The ratio of the anionic and cationic forms of molybdenum in the mother liquor depending on the acidity of the solution according to electrochromatography data

\begin{tabular}{|c|c|c|c|c|}
\hline \multirow[t]{2}{*}{ Solution name } & \multirow{2}{*}{$\begin{array}{l}\text { Sulfuric acid } \\
\text { content, g/L }\end{array}$} & \multirow{2}{*}{$\begin{array}{ll}\text { Sulfate } & \text { ion } \\
\text { content, g / L } \\
\text { (calculated) }\end{array}$} & \multicolumn{2}{|c|}{ Molybdenum fraction, $\%$} \\
\hline & & & Cationic & Anionic \\
\hline Sulfuric acid solution & 410 & 402 & $\sim 20$ & $\sim 80$ \\
\hline $\begin{array}{l}\text { Sulfuric acid solution, diluted with } \\
\text { water } 2 \text { times }\end{array}$ & 205 & 201 & $\sim 40$ & $\sim 60$ \\
\hline $\begin{array}{l}\text { Sulfuric acid solution } \\
\text { diluted with water } 2 \text { times }\end{array}$ & 102,5 & 100,5 & $\sim 70$ & $\sim 30$ \\
\hline $\begin{array}{l}\text { Sulfuric acid solution, } \\
\text { neutralized with ammonia, added } \\
220 \mathrm{ml} / \mathrm{I}\end{array}$ & 200 & 328 & $\sim 30$ & $\sim 70$ \\
\hline $\begin{array}{l}\text { Sulfuric acid solution, neutralized } \\
\text { with ammonia, added } 220 \mathrm{ml} / \mathrm{I}\end{array}$ & 100 & 291 & $\sim 50$ & $\sim 50$ \\
\hline
\end{tabular}

The state of molybdenum in solution is characterized by equilibrium:

$$
\mathrm{MoO}_{2} \mathrm{SO}_{4}+(2 \mathrm{n}-2) \mathrm{H}_{2} \mathrm{SO}_{4} \leftrightarrow \mathrm{H}(2 \mathrm{n}-2)[\mathrm{MoO} 2(\mathrm{SO} 4) \mathrm{n}]
$$




\section{Ionic State of Molybdenum in Sulfuric Uterine Solutions of Rhenium Sorption and its Extraction}

With a decrease in the concentration of sulfuric acid, the equilibrium of this reaction shifts to the left, and the proportion of the cationic form in the form of neutral molybdenyl sulfate MoO2SO4 increases. Deeper neutralization of sulfuric acid leads to the formation of molybdic acid and further polymolybdates:

$$
\mathrm{MoO}_{2} \mathrm{SO}_{4}+2 \mathrm{NH}_{4} \mathrm{OH} \rightarrow \mathrm{H}_{2} \mathrm{MoO}_{4}+\left(\mathrm{NH}_{4}\right)_{2} \mathrm{SO}_{4} \text {. }
$$

Thus, for the sorption of molybdenum from sulfuric acid solutions, it is advisable to use anionites that are selective to the forms of the anions of molybdenyl sulfates $\left[\mathrm{MoO}_{2}\left(\mathrm{SO}_{4}\right)_{n}\right]^{-(2 \mathrm{n}-2)}$

To select an ion exchange resin for molybdenum in laboratory conditions, several grades of ion exchangers have been tested. Laboratory studies were carried out on technological mother liquors under static conditions. Experimental data are presented in Table 3.

Table 3. Results of sorption of molybdenum from mother liquor under static conditions sorbents converted to $\mathrm{H}+/ \mathrm{SO} 4-2$ formula (Ex. Solution:Mo - $6.3 \mathrm{~g} / \mathrm{l} ; \mathrm{H}_{2} \mathrm{SO}_{4}-400 \mathrm{~g} / \mathrm{l} ; \mathrm{Vp} / \mathrm{Vc}=10$ )

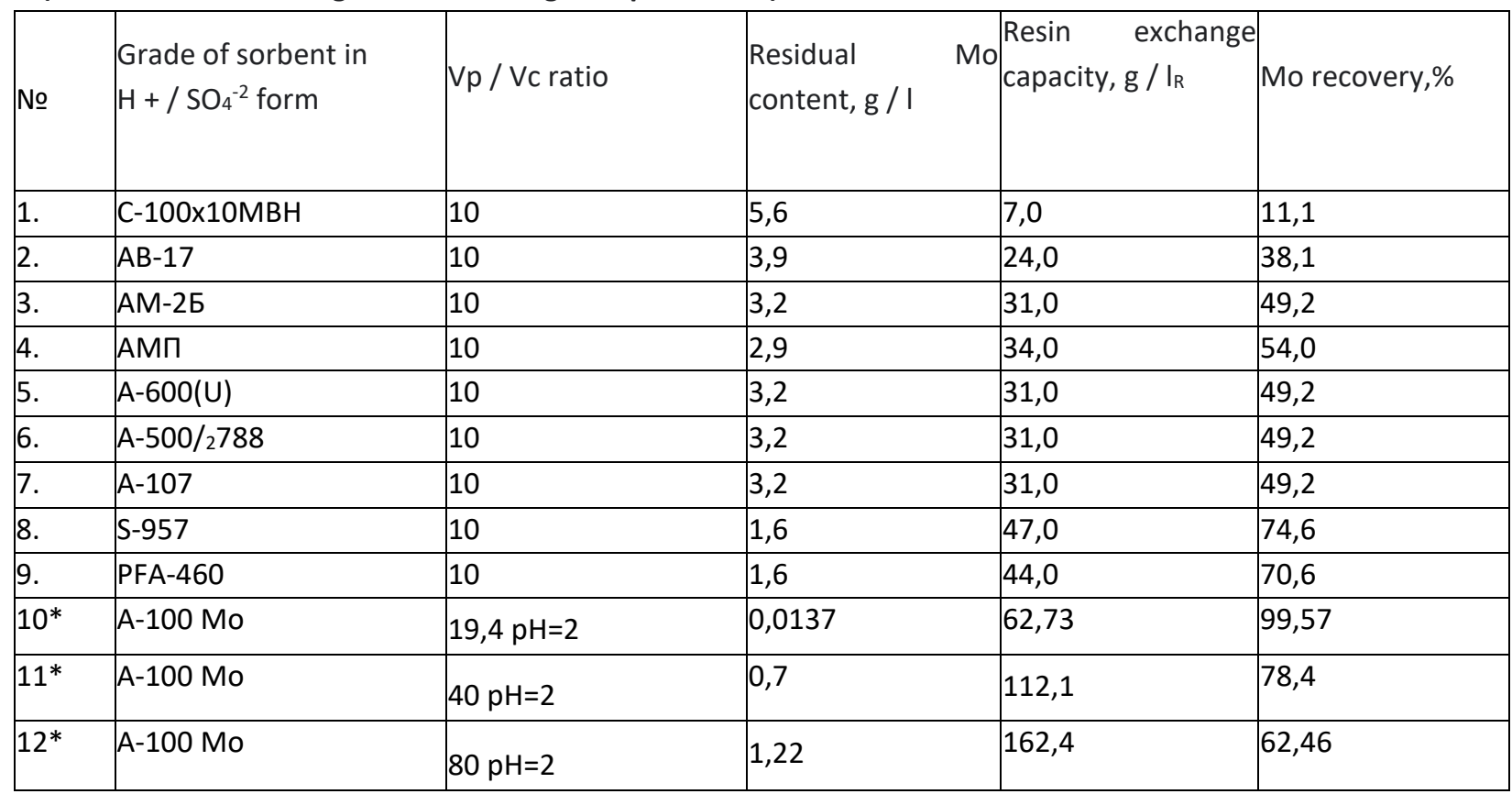

*) at $\mathrm{pH}=2$, the initial content of molybdenum in solutions is $3.25 \mathrm{~g} / \mathrm{I}$

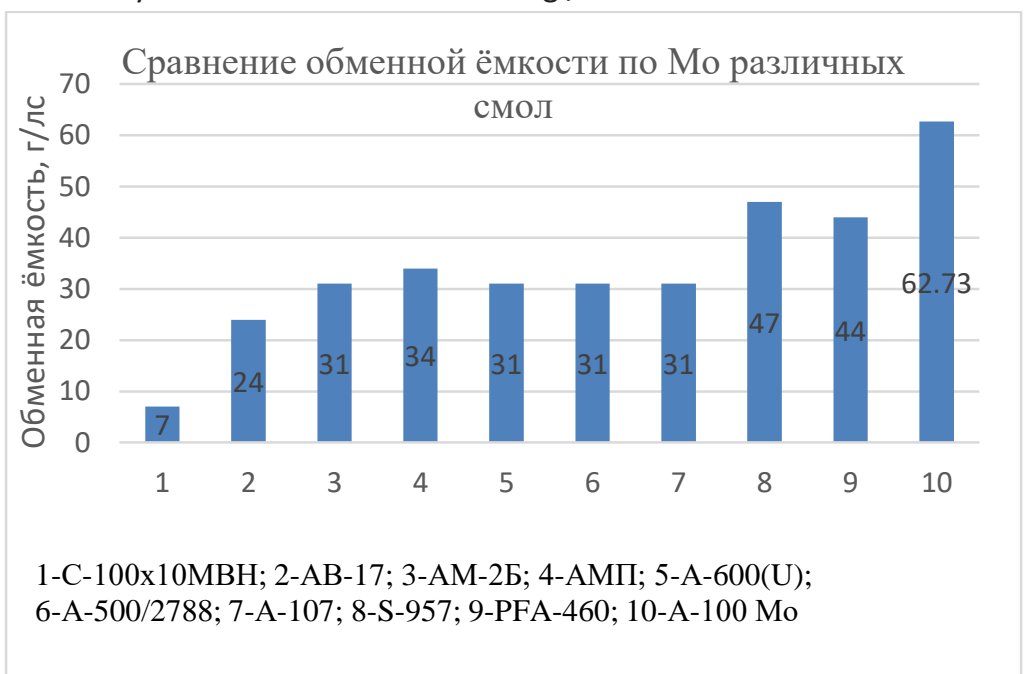

Fig. 1. Comparison of the exchange capacity of various ion-exchange resins for molybdenum from sulfuric acid solutions.

Using oxidative titration with a $0.1 \mathrm{~N}$ solution of potassium permanganate, it was found that there are no 4- and 5-valent molybdenum compounds in the solution, i.e. all molybdenum is present in the 6 -valent state. It was found that molybdenum is present in solutions in the form of $\mathrm{MoO}_{2}{ }^{2+}$ cations and anions in the composition of molybdenyl sulfate complexes $\left[\mathrm{MoO}_{2}\left(\mathrm{SO}_{4}\right)\right.$ n]. 


\section{Ionic State of Molybdenum in Sulfuric Uterine Solutions of Rhenium Sorption and its Extraction}

For ion-exchange sorption of molybdenum from more acidic solutions, the set of sorbents is limited and the sorption indices are insufficiently effective (Fig. 1). The main reasons for this are the significant competition of the sulfate ion during the sorption of molybdate - and polymolybdate - ions, as well as the variety of forms of molybdenum in solution (molybdenyl sulfates, molybdenyl - ion, molybdate, polymolybdates) and the processes of transformation of forms of molybdenum in the ion exchanger phase upon interaction with sulfate - and bisulfate - by ions [2].

According to the results of the extraction of molybdenum from sulfuric mother liquors, preference is given to macroporous weakly basic anion exchangers. For further testing and development of modes of sorption and desorption of molybdenum from sulfuric acid solutions, A-100 Mo and S-957 Purolite resins were selected.

Figure 2 shows the curve of molybdenum sorption on the A-100 Mo sorbent from the waste sulfuric acid mother liquor neutralized with ammonia to $\mathrm{pH}-2$.

As can be seen from Fig.3,4 separation of molybdenum from iron is achieved in both sorbents.

In fig. shows the spectra obtained on a scanning electron microscope JEOL JSM-IT200 with an energy dispersive attachment from A-100 Mo and S-957 Purolite resins before and after sorption.

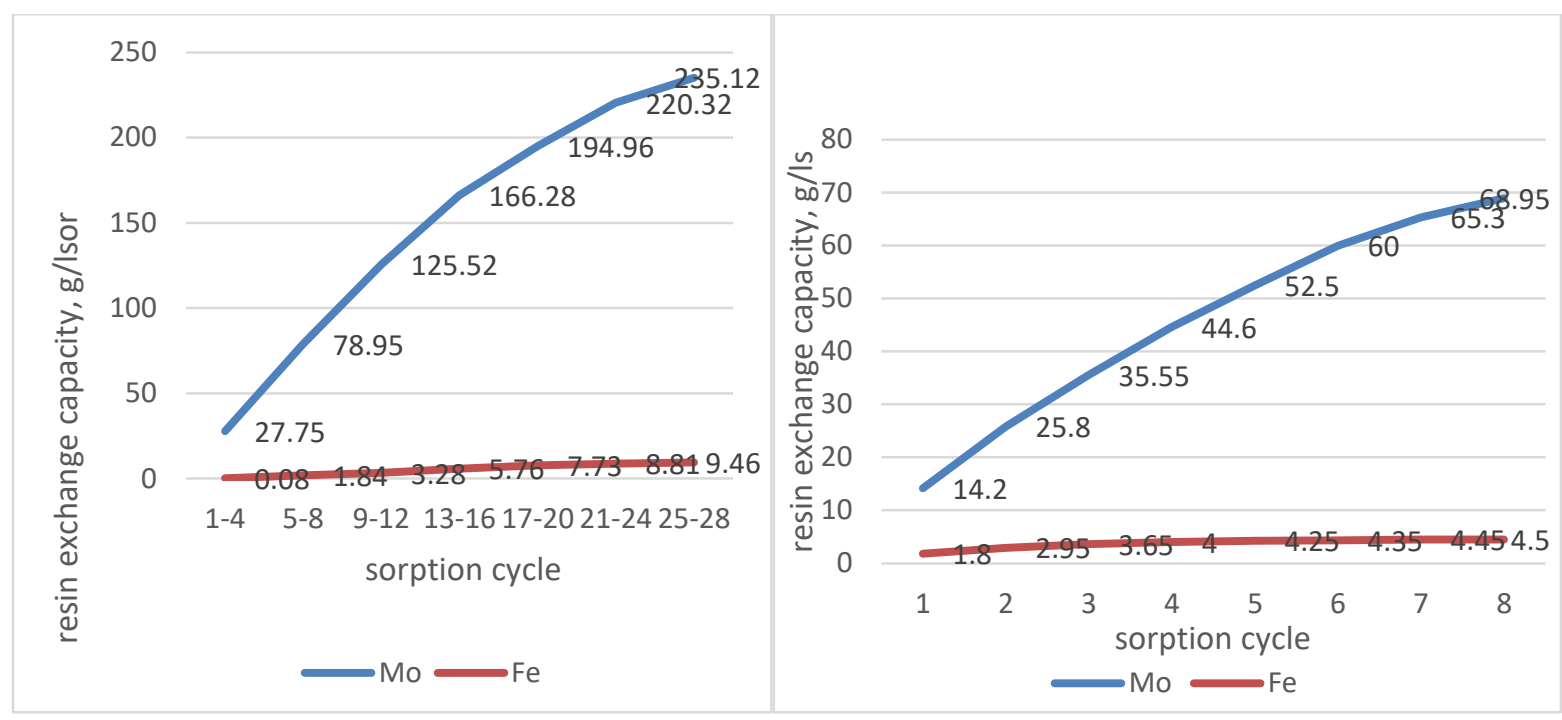

Fig.2 Curve of sorption of molybdenum on the sorbent A-100 Mo and S-957 from waste sulphate mother liquor neutralized with ammonia to $\mathrm{pH}-2$.
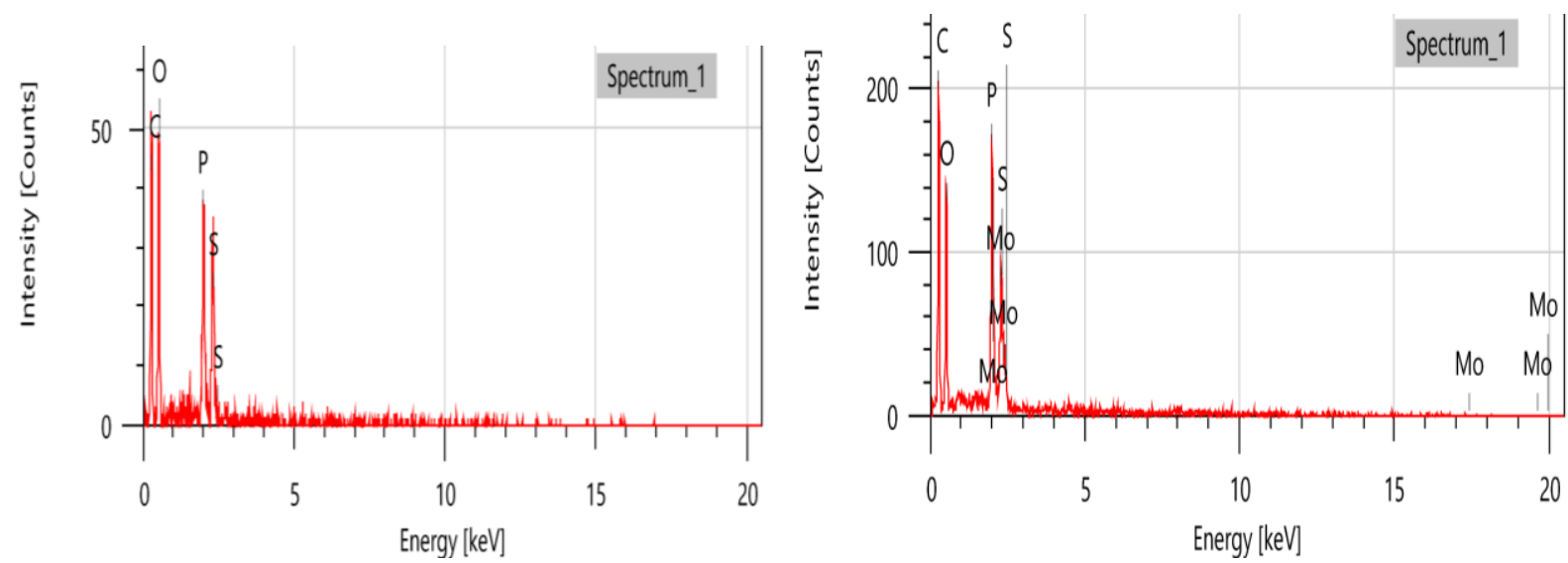

Fig. 3 SEM-EDX sorbent S-957 Purolite - before and after sorption of molybdenum

Fig 3,4. It is clearly seen that, as a result of sorption, along with the peaks of the sorbent atoms, the spectrum contains peaks belonging to molybdenum.

Desorption of molybdenum from the A-100Mo resin was carried out with an ammonia solution of 100-120 g / I (1: 1). To determine the desorption indices from the obtained saturated sorbent, desorption was carried out at a ratio $\mathrm{Vd} / \mathrm{Vc}=2: 1$ and a cycle duration of 2 hours. The total degree of desorption of molybdenum is $91.7 \%$.

Desorption of molybdenum from S-957 resin with $120 \mathrm{~g} / \mathrm{I}$ ammonia solution with addition of $100 \mathrm{~g} / \mathrm{I}$ ammonium sulfate, $30 \mathrm{~g} / \mathrm{I}$ hydrogen peroxide solution, Trilon B solution, in various combinations, duration -4 hours. 


\section{Ionic State of Molybdenum in Sulfuric Uterine Solutions of Rhenium Sorption and its Extraction}

Apparently, the rate of desorption of molybdenum from the S-957 sorbent is determined by the reaction rate:

$$
\mathrm{R} 2-\mathrm{MoO}_{2}{ }^{2+}+4 \mathrm{NH}_{4}{ }^{+} \rightarrow\left(\mathrm{NH}_{4}\right) 2 \mathrm{MoO}_{4}+2 \mathrm{R}-\mathrm{NH}_{4}
$$

one of the stages of which is the process:

$$
\mathrm{R}_{2} \mathrm{MoO}_{2}+2 \mathrm{NH}_{4}+\mathrm{OH}^{-} \rightarrow 2 \mathrm{RNH}_{4}+\mathrm{MoO}_{2}(\mathrm{OH})_{2} \rightarrow 2 \mathrm{RNH}_{4}+\mathrm{H}_{2} \mathrm{MoO}_{4}
$$

The low rate of desorption is apparently due to the course of the desorption process through several stages, and one of the slow stages may be the recombination of the molybdenyl ion in the sorbent phase into molybdic acid, which is then washed out by ammonia from the sorbent phase .

In fig. shows a microphotogram and ED-spectrum of the obtained product after desorption of A-100 Mo and S-957 Purolite resins (Fig. 4).

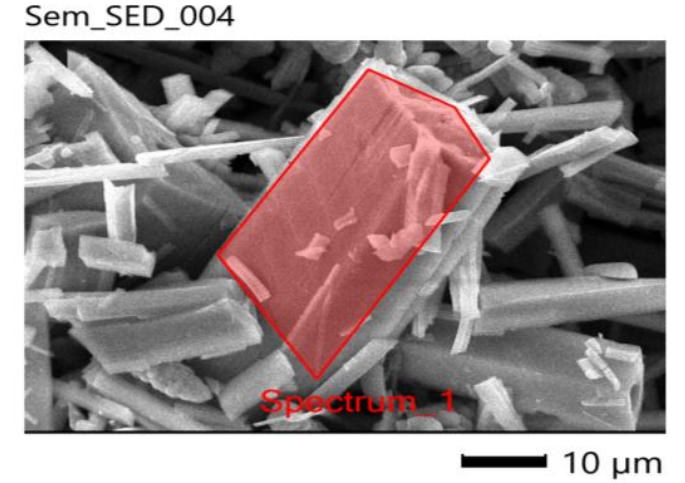

Spectrum_1

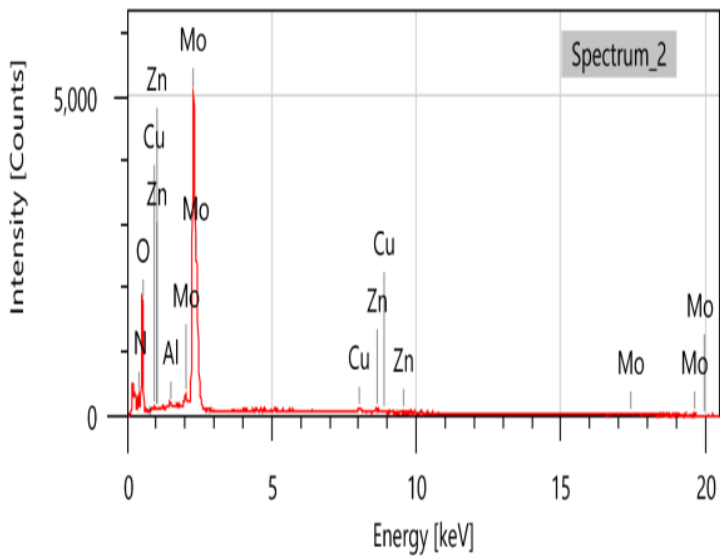

Fig 4 Microphotogram and ED-spectrum of the obtained technical ammonium tetramolybdate (ATM) product after desorption from A-100 Mo and S-957 Purolite resins

As a result of extended laboratory studies, a "rough" ATM was obtained, re-purified from impurities by fractional recrystallization. The compositions of the purified technical and ATM salt according to GOST 2677-78 are presented in table 10.

Table 4. Chemical composition of purified ATM, \% (*technical ATM, ** GOST 2677-78)

\begin{tabular}{|l|l|l|l|l|l|l|l|}
\hline $\mathrm{MoO}_{3}$ & $\mathrm{Fe}$ & As & $\mathrm{Ni}$ & $\mathrm{Si}$ & $\mathrm{Al}$ & $\mathrm{Mg}$ & $\mathrm{Mn}$ \\
\hline $76,9 *$ & 0,018 & 0,002 & 0.001 & 0,15 & 0,008 & 0,006 & 0,001 \\
\hline 77,5 & 0,0012 & 0,0012 & 0,0005 & 0,0013 & 0,0013 & 0,002 & 0,001 \\
\hline $78^{* *}$ & 0,007 & 0,003 & 0,002 & 0,01 & 0,002 & 0,0015 & 0,003 \\
\hline
\end{tabular}

IR and Raman spectra of ATM after purification are shown in fig. 7.
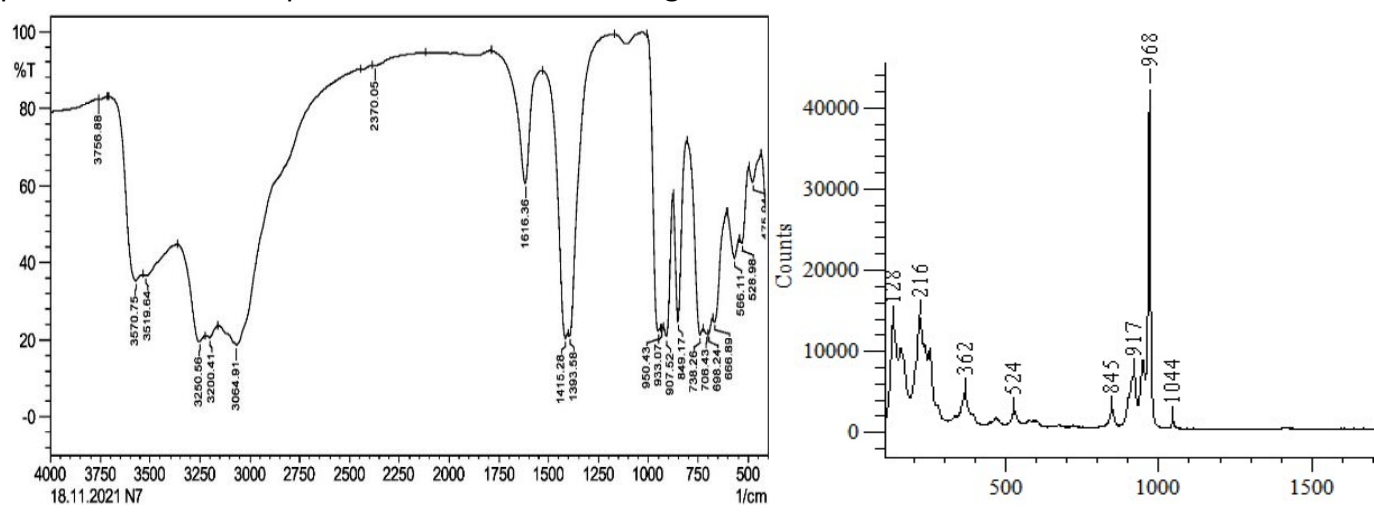

Fig. 5. IR and Raman spectra of ATM obtained from sulfuric acid solutions of rare metals plant

The value of the vibration frequency observed in the IR and Raman spectra of the obtained ATM corresponds to the data available in the literature. 


\section{Ionic State of Molybdenum in Sulfuric Uterine Solutions of Rhenium Sorption and its Extraction}

\section{CONCLUSIONS}

1. According to the results of electrochromatography of sulfuric mother liquors, it was found that molybdenum in this solution is present in anionic complexes of the $\left[\mathrm{MoO}_{2}\left(\mathrm{SO}_{4}\right)_{\mathrm{n}}\right]^{-(2 n-2)}$ type; molybdenyl sulfate complexes, and $\mathrm{MoO}_{2}{ }^{2+}$ cations in the composition of neutral molecules of molybdenyl sulfate $\mathrm{MoO}_{2} \mathrm{SO}_{4}$.

2. According to the preliminary laboratory studies, it was found that sorption is effective when using weakly basic macroporous anion exchangers and chelated cation exchangers.

3. Sorption proceeds efficiently at a specific load of 2 column volumes / hour. A $12 \%$ aqueous ammonia solution is recommended as a desorbing reagent. In this case, the degree of desorption of molybdenum from the sorbent phase into the eluate reaches $95 \%$.

\section{BIBLIOGRAPHY}

1) A. N. Zelikman, B.G. Korshunov. "Metallurgy of rare metals". Metallurgy, 1991, p. 44.

2) Shegai A.A., Sharipov Kh.T., Shegai M.A. Technology of molybdenum and materials based on it. - Tashkent: FAN and technology, 2010, p. 255.

3) Zagorodnyaya A.N., Abisheva Z.S., Sadykanova S.E., Sharipova A.S. Preparation of solutions from washing metallurgical gases of copper production for sorption extraction of rhenium from them // Mater. II Int. Kazakh-Russian conf. in chemistry and chemical technology. Karaganda. 2012.Vol. 1.p.138-142.

4) Abisheva Z.S., Zagorodnyaya A.N., Bekturganov N.S., Ospanov E.A., Ospanov N.A. Investigation of the sorption of rhenium from industrial solutions of washing sulfuric acid of the Balkhash copper-smelting plant on anion-exchange resin A170. Non-ferrous metals. 2012, №7, p. 57-61.

5) Ergozhin E.E., Chalov T. K., Kovrigina. T.V., Melnikov E.A., Nikitina A.I. Sorption of molybdenum (VI) ions by new synthetic sorbents. Russian Journal of Applied Chemistry. 2017. Vol. 90.

6) M.H. Umarahunov, Yu.A.Sadykova, G.A. Hodzhaeva, Zhurnal fizicheskoj himii, 2011, Vol. 85, no.2, p. 391-393.

7) A.A. Blokhin, A.A. Amosov, Yu.V. Murashkin. Assessment of the possibility of sorption extraction of rhenium from washing sulfuric acid of wet gas cleaning systems of copper-nickel production. Non-ferrous metals. 2006. \# 8. p. 94-98.

8) A.M. Kunaev, A.Yu. Dadabaev, E.G. Tarasova. "Ion exchange processes in the hydrometallurgy of non-ferrous metals." Alma-Ata, 1986, p. 248.

9) E.E. Maltseva, A.A. Blokhin, M.A. Mikhailenko, Yu.V. Murashkin Effect of solution acidity on the sorption of rhenium and molybdenum on some weakly basic anion exchangers. // Sorption and chromatographic processes 2012, no. 1, p. 78-84. 